\title{
$\mathrm{SiO}_{2}$ 粒子が孤立したフェライト・ $\mathrm{SiO}_{2}$ 複合電磁波吸収体の特性評価
}

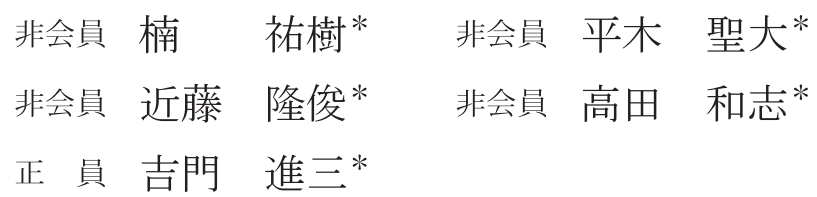

\section{Characteristics of the Electromagnetic Wave Absorbers of Composites Made of Ni-Zn Ferrite and Isolated $\mathrm{SiO}_{2}$ Particles}

Hiroki Kusunoki*, Non-member, Kiyohiro Hiraki*, Non-member, Takatoshi Kondo*, Non-member Kazushi Takada*, Non-member, Shinzo Yoshikado*, Member

It is found from simulation study that electromagnetic wave absorbers made of composites of $\mathrm{Ni}-\mathrm{Zn}$ ferrite and $\mathrm{SiO}_{2}$ particles, which are mutually isolated each other in the continuous medium of $\mathrm{Ni}-\mathrm{Zn}$ ferrite, show absorption in the frequency region both below and above $1 \mathrm{GHz}$. The spray method is proposed to fabricate such composites in this study. The thin films of Ni- $\mathrm{Zn}$ ferrite can be coated on the surface of $\mathrm{SiO}_{2}$ particles by the spray thin film deposition method. It is confirmed by XRD and the electromagnetic characteristics measurement. The measured complex permeability approached to the calculated result using the isolation model of $\mathrm{SiO}_{2}$ particles in the Ni- $\mathrm{Zn}$ ferrite medium than using Lichtenecker's logarithm mixed low.

キーワード : 複合電磁波吸収体, $\mathrm{Ni}-\mathrm{Zn}$ フェライト, $\mathrm{SiO}_{2}$, 複素比透磁率, スプレー法, 表面被覆

Keywords : composite electromagnetic wave absorber, $\mathrm{Ni}-\mathrm{Zn}$ ferrite, $\mathrm{SiO}_{2}$, complex permeability, spray method, surface coating

\section{1. はじめに}

金属を裏打ちした単層型電磁波吸収体において, 試料の 複素比透磁率 $\mu_{\mathrm{r}}{ }^{*}$ ，複素比誘電率 $\varepsilon_{\mathrm{r}}{ }^{*}$ の周波数特性は，所望 の吸収特性を示す電磁波吸収体を設計するにあたり重要な 要素である(1) (6)。ところで目的とする周波数領域において 良好な吸収特性を示す電波吸収体材料を開発するために単 一の組成の材料を用いるよりは磁性体と誘電体の複合体を 用いる方が $\mu_{\mathrm{r}}{ }^{*}$ および $\varepsilon_{\mathrm{r}}{ }^{*}$ を制御できる範囲が広がると考え られる。

2 種類以上の材料を混合してどちらの物質も粒子として 孤立せずお互いに接触している場合，複合体の平均の $\mu_{\mathrm{r}}{ }^{*}$ あ るいは $\varepsilon_{\mathrm{r}}{ }^{*}$ をちえるもとして Lichtenecker の対数混合則が 知られている ${ }^{(4)(7)}$ 。Lichtenecker の対数混合則を用いること により，複合体の電磁気的特性は，混合する各物質の電磁 気的特性と体積混合率のみにより算出することが可能であ る。しかし, 複合磁性体材料を構成するフェライト, ある いは $\mathrm{SiO}_{2}$ のどちらか一方の粒子が他方の物質媒質の中に孤 立した複合体の電磁気的特性は Lichtenecker の対数混合則 に従わず， $\mathrm{Ni}-\mathrm{Zn}$ フェライト粒子あるいは $\mathrm{SiO}_{2}$ がもう片方

\footnotetext{
* 同志社大学工学部

干610-0321 京田辺市多々羅都谷 1-3

Faculty of Engineering, Doshisha University

1-3, Tatara-Miyakodani, Kyotanabe 610-0321
}

の物質の中に孤立したモデルで定性的に説明される。実際 に $\mathrm{Ni}-\mathrm{Zn}$ フェライトが $\mathrm{SiO}_{2}$ 中に孤立する度合を大きくした 複合体を作製したところこのモデルから求めた電磁気的特 性の值に近づくことをすでに報告した ${ }^{(6)}$ 。

本研究の目的は複合磁性材料を構成するフェライト媒質 中で誘電率の小さい $\mathrm{SiO}_{2}$ 粒子を孤立させた場合の電磁波吸 収特性を評価することである。すでに $\mathrm{SiO}_{2}$ 粒子が $\mathrm{Ni}-\mathrm{Zn}$ フ エライト媒質中に孤立したモデルに対して，その複合体の 電磁気的特性および電磁波吸収特性を実測およびシミュレ ーションにより評価した ${ }^{(6)}$ 。シミュレーションの結果，この 複合体を用いた単層型電磁波吸収体では組成を変化させる ことなく $1 \mathrm{GHz}$ 以下の周波数領域では整合厚は増加寸るも のの, Ni-Zn フェライト単体と同程度の吸収帯域幅が得られ ると同時に, $1 \mathrm{GHz}$ 以上の周波数帯域においても $99 \%$ 以上の 電磁波が吸収されることがわかった。

そこで本研究において $\mathrm{Ni}-\mathrm{Zn}$ フェライト媒質中で $\mathrm{SiO}_{2}$ 粒 子が孤立する割合を大きくすることが可能であるかを検討 した。 $\mathrm{SiO}_{2}$ 粒子と $\mathrm{Ni}-\mathrm{Zn}$ フェライトの超微粒子を用いて焼 結体を作製する方法と $\mathrm{Ni}-\mathrm{Zn}$ フェライト焼結体中に $\mathrm{SiO}_{2}$ が 孤立するようにするためスプレー法を用いて $\mathrm{SiO}_{2}$ 粒子表面 をあらかじめ Ni-Zn フェライト薄膜で被膜する方法を用い て作製した複合材料の電磁気的特性および電磁波吸収特性 を評価したので報告する。 


\section{2. 実験原理}

2 種類の物質を混合した混合体の平均複素比透磁率 $\mu_{\mathrm{r}}{ }^{*}$ および平均複素比誘電率 $\varepsilon_{\mathrm{r}}{ }^{*}$ の周波数特性を説明する混合 則である Lichtenecker の対数混合則は次式で与えられる(7)。

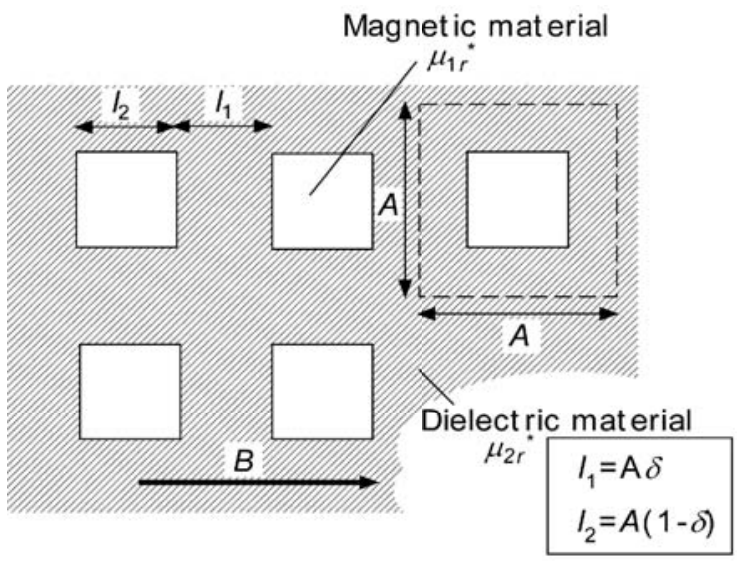

図 1 透磁率 $\mu_{1 \mathrm{r}}{ }^{*}$ の立方体粒子が透磁率 $\mu_{2 \mathrm{r}}{ }^{*}$ の媒質中に 均等に孤立したモデル

Fig. 1. The model with cubic grains of $\mu_{1 \mathrm{r}}{ }^{*}$ in a medium of $\mu_{2 \mathrm{r}}{ }^{*}$.

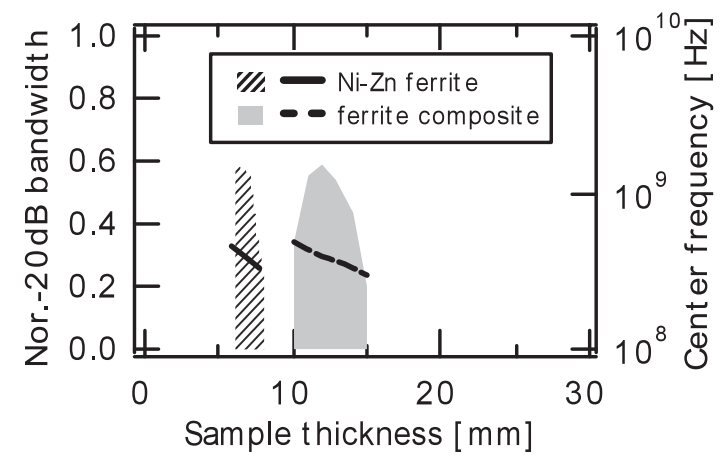

(a) $\mathrm{SiO}_{2}$ of $50 \mathrm{~mol} \%$

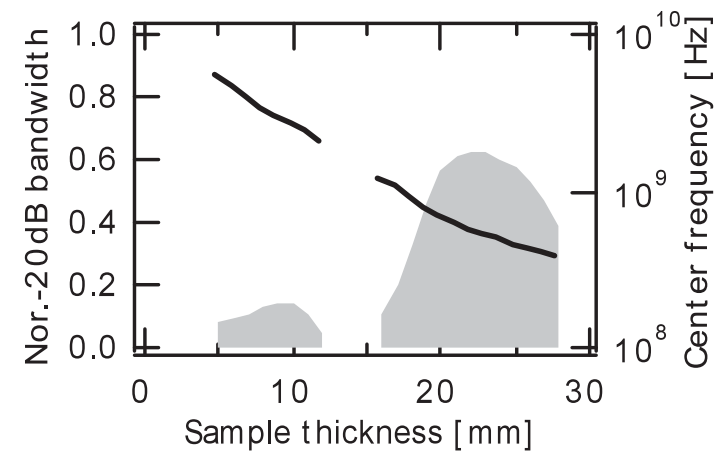

(b) $\mathrm{SiO}_{2}$ of $80 \mathrm{~mol} \%$

図 $2 \mathrm{SiO}_{2}$ 粒子が $\mathrm{Ni}-\mathrm{Zn}$ フェライト媒質中に完全に 孤立した複合体の吸収中心周波数と規格化

-20dB 帯域幅のシミュレーション值

Fig. 2. Simulated values of normalized $-20 \mathrm{~dB}$ bandwidth and absorbing center frequency of the composite in which $\mathrm{SiO}_{2}$ particles are completely isolate by $\mathrm{Ni}-\mathrm{Zn}$ ferrite medium.

$$
\begin{aligned}
& \log \mu_{r}^{*}(\omega)=\delta_{1} \log \mu_{1 r}^{*}(\omega)+\delta_{2} \log \mu_{2 r}^{*}(\omega) \\
& \log \varepsilon_{r}^{*}(\omega)=\delta_{1} \log \varepsilon_{1 r}^{*}(\omega)+\delta_{2} \log \varepsilon_{2 r}^{*}(\omega)
\end{aligned}
$$

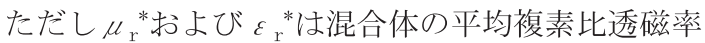
および平均複素比誘電率。 $\mu_{1 \mathrm{r}}{ }^{*}, \varepsilon_{1 \mathrm{r}}{ }^{*}$ および $\mu_{2 \mathrm{r}}{ }^{*}$, $\varepsilon_{2 \mathrm{r}}{ }^{*}$ は各物質の複素比透磁率, 複素比誘電率。 $\delta_{1}$ および $\delta_{2}$ は各物質の混合体積率。

混合体の電磁気的特性が Lichtenecker の対数混合則に従 うとすれば，その複合体の電磁気的特性を混合する各物質 の電磁気的特性とその体積混合率のみにより算出すること が可能である ${ }^{(6)}$ 。

$\mathrm{Ni}-\mathrm{Zn}$ フェライトは $\mathrm{SiO}_{2}$ とほとんど固溶体を作らず，焼 結体は混合体になることが報告されている(4)。平均複素比透 磁率 $\mu_{\mathrm{r}}{ }^{*}$ の周波数特性は, 図 1 に示されるモデルのように複 素比透磁率 $\mu_{1 \mathrm{r}}{ }^{*}$ の粒子が複素比透磁率 $\mu_{2 \mathrm{r}}{ }^{*}$ の磁性体媒質中 に孤立したモデルを用いて説明される。この時, 複合体の 平均複素比透磁率 $\mu_{\mathrm{r}}{ }^{*}$ は以下のようになる ${ }^{(6)}$ 。

$$
\begin{aligned}
& \mu_{r}^{*}=\mu_{2 r}^{*}\left\{\frac{(1-\delta)^{2}+\delta^{2}(2-\delta)+\frac{\mu_{2 r}^{*}}{\mu_{1 r}^{*}} \delta(1-\delta)(2-\delta)}{\delta+\frac{\mu_{2 r}^{*}}{\mu_{1 r}^{*}} \delta(1-\delta)}\right\} \\
& \delta=1-\exp \left(\frac{\ln \delta_{2}}{3}\right)
\end{aligned}
$$

図 2 に $\mathrm{SiO}_{2}$ の混合量が $50 \mathrm{~mol} \%$ と $80 \mathrm{~mol} \%$ の複合体の式(3) より求めた $\mu_{\mathrm{r}}{ }^{*}$ の值を用いて計算した吸収中心周波数につ いて規格化した-20dB 吸収帯域幅の計算值を示す。平均複素 比誘電率 $\varepsilon_{\mathrm{r}}{ }^{*}$ として, $\mathrm{SiO}_{2}$ の複素比誘電率を 3.8- 0 として体 積比より算出した值を用いた。 $\mathrm{SiO}_{2}$ を $50 \mathrm{~mol} \%$ 混合した場 合, $\mathrm{Ni}-\mathrm{Zn}$ フェライトの微細粉を用いた複合体では, 整合厚 が厚くなるが Ni-Zn フェライト単体と同程度の吸収中心周 波数および-20dB 帯域幅が得られる。従って, この混合体で は目立った改善は見られない。一方, $\mathrm{SiO}_{2}$ を $80 \mathrm{~mol} \%$ 混合し た場合, 整合厚は異なるが低周波数領域と高周波数領域の 両方において-20dB 以下の良好な吸収特性を示す。これは低 周波領域では $\mu_{\mathrm{r}}{ }^{*}$ 周波数特性が $\mathrm{Ni}-\mathrm{Zn}$ フェライトと似ている ことと, 高周波領域では $\mu_{\mathrm{r}}{ }^{*}$ の実部が $\mathrm{Ni}-\mathrm{Zn}$ フェライトより も大きくなるためである(6)。

\section{3. 実験方法}

〈3・1〉試料の作製 Ni-Zn フェライト超微粒子一 $\mathrm{SiO}_{2}$ 複合体 : Ni-Zn フェライト中に $\mathrm{SiO} 2$ 粒子が孤立するよ うに, 平均粒径約 $10 \mathrm{~nm}$ の $\mathrm{Ni}-\mathrm{Zn}$ フェライト超微粒子 $\mathrm{Ni}_{0.351} \mathrm{Zn}_{0.637} \mathrm{Fe}_{2.008} \mathrm{O}_{4}$ (堺化学工業, FNZ-1) および焼結補助剤 $\mathrm{B}_{2} \mathrm{O}_{3}$ を 3 mass\% \%電子天秤にて計量を行う。計量した試料をメ ノウ乳鉢で, 純水で 1 時間湿式混合を行い, Ni-Zn フェライ ト超微粒子を十分に分散させた後, Ni-Zn フェライト中に 


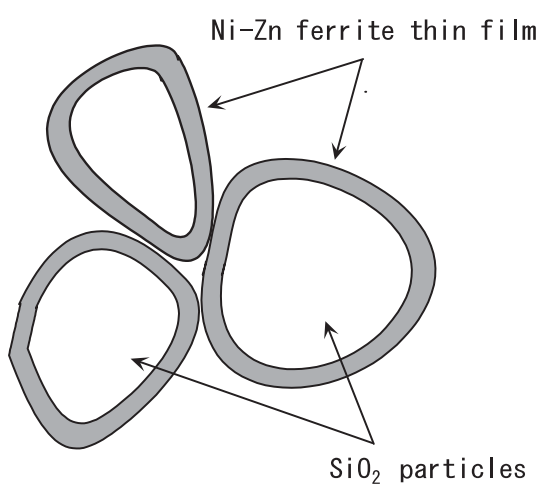

図３スプレー法を用いて $\mathrm{SiO}_{2}$ 粒子表面に $\mathrm{Ni}-\mathrm{Zn}$ フェライト被膜を作製した試料の概念図

Fig. 3. Schematic drawing of the $\mathrm{SiO}_{2}$ particles coated by $\mathrm{Ni}-\mathrm{Zn}$ ferrite thin films using spray method.

$\mathrm{SiO}_{2}$ 粒子が孤立しやすいように平均粒径約 $200 \mathrm{~mm}$ の $\mathrm{SiO}_{2}$ (ケイ砂, ナカライテスク) を添加し $\mathrm{SiO}_{2}$ 粒子を粉砕しな いように混合を行う。その後加圧成形（320MPa）を行い直 径 $20 \mathrm{~mm}$ のペレットを作製し，ホットプレス法により約 $29 \mathrm{MPa}$ で $1100^{\circ} \mathrm{C} ， 2$ 時間焼成を行って焼結体を得る。

〈3·2〉 スプレ一法による Ni-Zn フェライト被膜の作製 $\mathrm{Ni}\left(\mathrm{NO}_{3}\right)_{2} \cdot 6 \mathrm{H}_{2} \mathrm{O}, \mathrm{Zn}\left(\mathrm{NO}_{3}\right)_{2} \cdot 6 \mathrm{H}_{2} \mathrm{O}, \mathrm{Fe}\left(\mathrm{NO}_{3}\right)_{3} \cdot 9 \mathrm{H}_{2} \mathrm{O}$ を所 定量混合した水溶液を $400^{\circ} \mathrm{C}$ 付近に加熱したガラス基板に 噴霧すると Ni-Zn フェライト薄膜が堆積することが報告さ れている ${ }^{(8)}$ 。従ってこの方法を $\mathrm{SiO}_{2}$ 粒子に応用した場合, 困 3 に示すように粒子の表面を $\mathrm{Ni}-\mathrm{Zn}$ フェライト薄膜で被 膜できると考えられる。〈3・1〉節の $\mathrm{Ni}-\mathrm{Zn}$ フェライト超微粒 子の $\mathrm{Ni}, \mathrm{Zn}$ と $\mathrm{Fe}$ のモル比と同じになるように $\mathrm{Ni}\left(\mathrm{NO}_{3}\right)_{2}$ • $6 \mathrm{H}_{2} \mathrm{O}$ を $0.348 \mathrm{~g}(0.007 \mathrm{M}), \mathrm{Zn}\left(\mathrm{NO}_{3}\right)_{2} \cdot 6 \mathrm{H}_{2} \mathrm{O}$ を $0.566 \mathrm{~g}(0.013 \mathrm{M})$, $\mathrm{Fe}\left(\mathrm{NO}_{3}\right)_{3} \cdot 9 \mathrm{H}_{2} \mathrm{O}$ を $2.424 \mathrm{~g}(0.040 \mathrm{M})$ 計量し純水 $150 \mathrm{~g}$ に溶解し て水溶液を作製した。この割合で作製した水溶液を濃度 $\mathrm{A}$ の水溶液とし，これに対して水溶液濃度 2 倍(B)，5 倍(C)お よび 100 倍(D)のものを作製した。図 4 に示すように平均粒 径約 $200 \mathrm{~mm}$ の $\mathrm{SiO}_{2}$ （石英砂，ナカライテスク）をステンレ ス容器に入れ，ホットプレートにより約 $400 \sim 500^{\circ} \mathrm{C} に$ 加熱 し, 水溶液をスプレーガンにより噴霧する。噴霧直後, 温 度が低下寸るため, 温度が噴霧前まで回復するまで待ち, 再び水溶液を噴霧する。これを繰り返し, Ni-Zn フェライト 被膜を $\mathrm{SiO}_{2}$ 粒子の表面に堆積させる。これに<3・1 節で用い た Ni-Zn フェライト超微粒子を加えて所定の混合量に調整 し加圧成形（320MPa）を行い，直径 $20 \mathrm{~mm}$ ペレットを作製 し，ホットプレス法により約 $29 \mathrm{MPa}$ で $1100^{\circ} \mathrm{C} ， 2$ 時間焼成 を行って焼結体を得る。

〈3·3〉評価方法得られた焼結体をトロイダルコア 状（外径: 約 $7 \mathrm{~mm}$, 内径 : 約 $3 \mathrm{~mm}$ ) に加工し, 同軸線路に 隙間ができないように装荷する。同軸管壁との接触を良く するためにトロイダルコアの内外側面に導電性ペースト(藤 倉化成, D-500)を塗布する。ベクトルネットワークアナライ

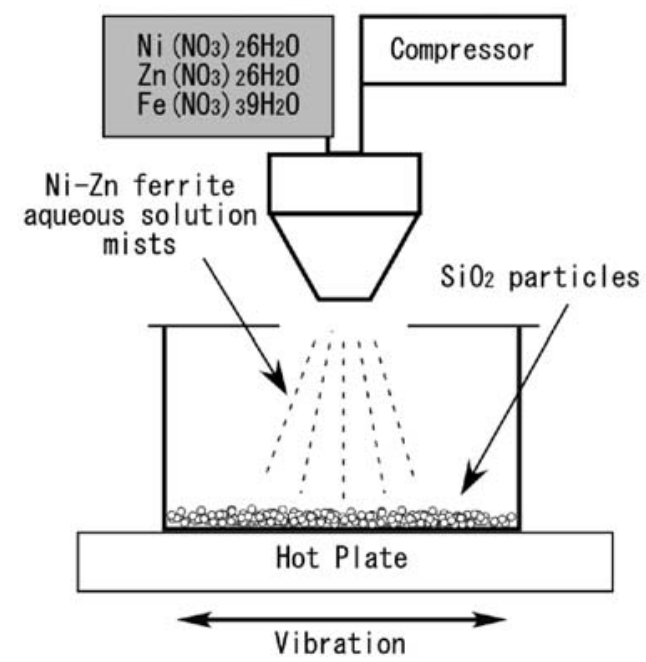

図4 スプレー法による $\mathrm{SiO}_{2}$ 粒子表面への $\mathrm{Ni}-\mathrm{Zn}$ フェライト被膜作製法

Fig. 4. Coating technique of Ni-Zn ferrite thin film on the surfaces of $\mathrm{SiO}_{2}$ particles.

ザ（アジレントテクノロジー，8719ES，8722ES）を用いて 2 port 法により Sパラメータの反射係数 $S_{11}$ および透過係 数 $S_{21}$ を測定し, 複素比誘電率, 複素比透磁率およびリター ンロスを算出する(6)(7)。リターンロス $R$ は以下の式で表され る。

$$
R=20 \log _{10}|\Gamma|
$$

ただし $\Gamma は$ 試料前面における複素電圧反射係数

X線回折装置（Rigaku，Miniflex）を用いて複合体および 被膜の構造を評価した。 $\mathrm{SiO}_{2}$ 粒子表面の観察には全体的に 焦点が合った画像が得られる光学顕微鏡(NIKON ECLIPSE ME600 および All-in-Focus)を用いた。

\section{4. 実験結果および考察}

〈4·1〉 Ni-Zn フェライト超微粒子と $\mathrm{SiO}_{2}$ の複合体の複 素比透磁率 Ni-Zn フェライトの連鎖ができるように, 焼 結補助剂 $\mathrm{B}_{2} \mathrm{O}_{3}$ を 3 mass \% 添加し, ホットプレス法により充 填率の向上を図った。 $\mathrm{Ni}-\mathrm{Zn}$ フェライトに $\mathrm{SiO}_{2}$ を混合させ た複合体は, 密度の増加に伴い導電性が増加し, 吸収特性 が劣化するが, $\mathrm{MnO}$ 等を少量添加することにより導電性を 低減させることが可能である(6)。しかし，ここではこのよう な添加物を添加しないで焼結体を作製した。

$\mathrm{Ni}-\mathrm{Zn}$ フェライト超微粒子に $\mathrm{SiO}_{2}$ を $70 \mathrm{~mol} \%$ 混合した複合 体に焼結補助剂 $\mathrm{B}_{2} \mathrm{O}_{3}$ を 3 mass\%添加した場合の複素比透磁 率 $\mu_{\mathrm{r}}{ }^{*}$ の実部 $\mu^{\prime}$ および虚部 $\mu^{\prime \prime}$ の周波数特性を図 5 に示 す。 $\mathrm{SiO}_{2}$ を $70 \mathrm{~mol} \%$ 混合した複合体において， $\mu^{\prime}$ の周波数 特性は高周波側で平坦化し， $\mu^{\prime \prime}$ は低周波側で大きくなり， 周波数特性はほぼ Lichtenecker の対数混合則から計算され るものと同様であった。これは $\mathrm{Ni}-\mathrm{Zn}$ フェライト超微粒子を 


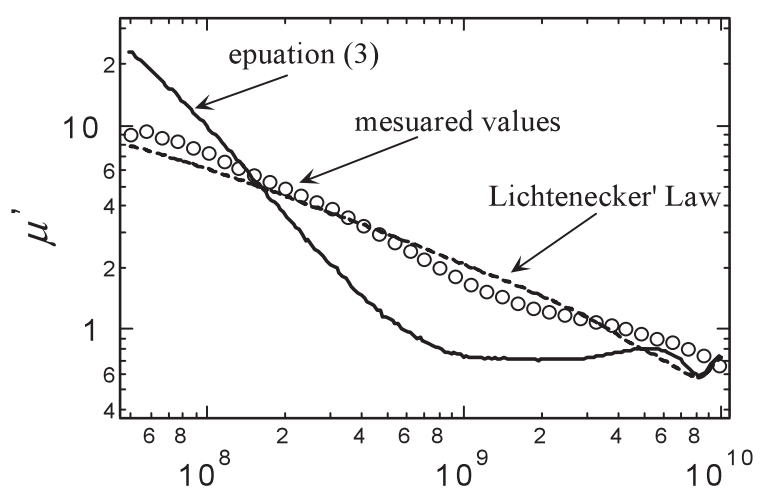

Frequency $[\mathrm{Hz}]$

(a)

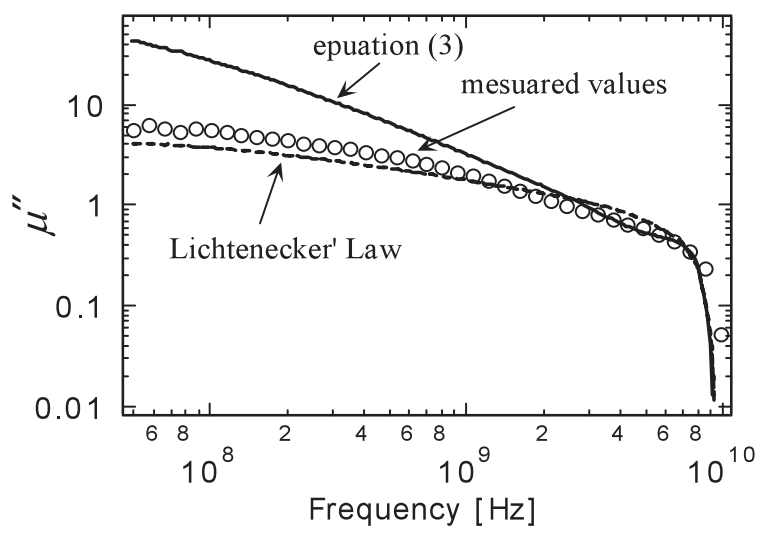

(b)

図 $5 \mathrm{Ni}-\mathrm{Zn}$ フェライトに $\mathrm{SiO}_{2}$ を70mol\%混合した 複合体の複素比透磁率 $\mu_{\mathrm{r}}{ }^{*}$ の周波数特性

Fig. 5. Frequency dependence of (a) the real part and (b) the imaginary part of $\mu_{\mathrm{r}}^{*}$ for composite materials made of super fine grain of $\mathrm{Ni}-\mathrm{Zn}$ ferrite- $30 \mathrm{~mol} \%$ and $\mathrm{SiO}_{2}-70 \mathrm{~mol} \%$. Plots show measured values.

用いても $\mathrm{Ni}-\mathrm{Zn}$ フェライト中に $\mathrm{SiO}_{2}$ を孤立させることがで きず, Ni-Zn フェライトの連鎖が弱かったためであると考え られる。この原因として Ni-Zn フェライト粒子の作製過程に おいてチーズと呼ばれる水分を含んだ超微粒子を乾燥させ る際に粒子同士が弱く結合したことが考えられる。従って 乾燥工程の前段階で $\mathrm{SiO}_{2}$ 粒子と混合することが必要である と考えられる。また焼結の段階で $\mathrm{Ni}-\mathrm{Zn}$ フェライトは $\mathrm{SiO}_{2}$ 超微粒子の場合と異なり, 粘性が大きいか表面張力が大き いために $\mathrm{SiO}_{2}$ 粒子の周りを十分に被覆できないことが原因 の 1 つであると考えられる。

〈4·2〉 スプレー法により作製した複合体の特性 眓 6 にスプレー法を用いて $\mathrm{SiO}_{2}$ 粒子表面に $\mathrm{Ni}-\mathrm{Zn}$ フェライト 被膜を堆積させた試料の XRD 回折結果を示す。 Ni-Zn フェ ライト被膜を堆積させた $\mathrm{SiO}_{2}$ 粒子を $1000^{\circ} \mathrm{C}, 1$ 時間で熱ア ニール後，粒子を粉砕して測定を行った。濃度 D の水溶液 を用いた場合には, $2 \theta$ が 35 度付近に Ni-Zn フェライトの回 折ピークが確認された。これ以外の濃度では膜の成長速度

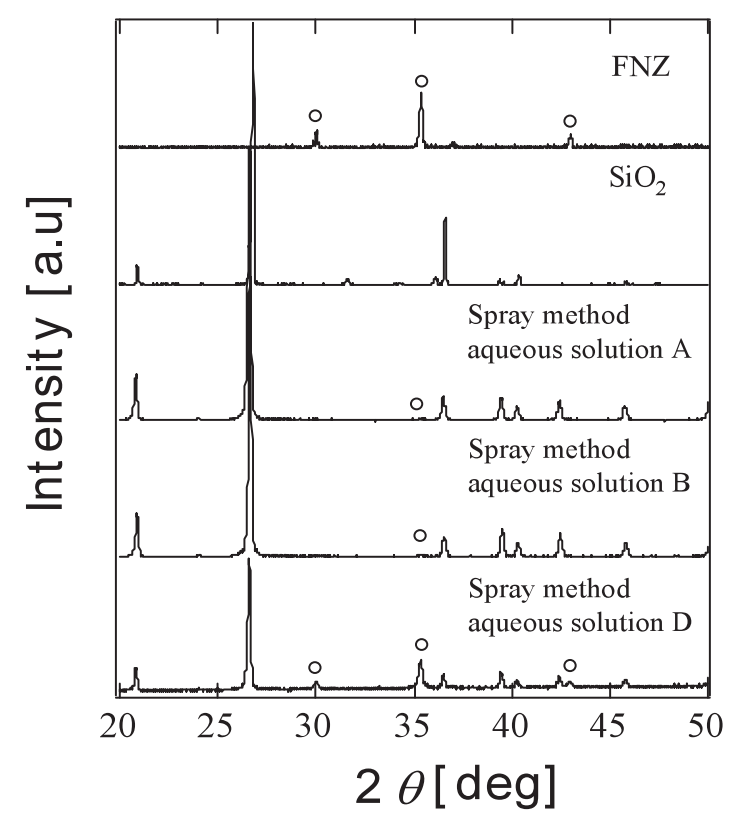

四 6 スプレー法を用いて $\mathrm{Ni}-\mathrm{Zn}$ フェライト被膜を 作製した $\mathrm{SiO}_{2}$ 粒子の $\mathrm{XRD}$ パターン

Fig. 6. XRD patterns of $\mathrm{SiO}_{2}$ particles coated $\mathrm{Ni}-\mathrm{Zn}$ ferrite by spray method.

が極端に小さく, ほとんど Ni-Zn フェライトのピークは観測 されなかった。以上のようにスプレー法により $\mathrm{SiO}_{2}$ 粒子表 面に Ni-Zn フェライト被膜を堆積させることが可能である ことがわかった。

スプレー法を用いて $\mathrm{Ni}-\mathrm{Zn}$ フェライト被膜を堆積させた $\mathrm{SiO}_{2}$ 粒子の表面の光学顕微鏡写真を図 7 に示す。濃度 D の 水溶液を用いて $\mathrm{Ni}-\mathrm{Zn}$ フェライト被膜を作製したものは $\mathrm{SiO}_{2}$ 表面に $\mathrm{Ni}-\mathrm{Zn}$ フェライト被膜が厚く堆積しているが, 膜厚にはむらがあり, 部分的に膜がはがれて被覆されてい ないところがあることがわかった。

図 8 に濃度 $\mathrm{A}$ および D の水溶液を用いてスプレー法によ り $\mathrm{Ni}-\mathrm{Zn}$ フェライト被膜を堆積させた $\mathrm{SiO}_{2}$ を用いて作製し た複合体の複素比透磁率を示す。濃度 $\mathrm{D}$ の水溶液を用いて $\mathrm{Ni}-\mathrm{Zn}$ フェライト被膜を堆積させた $\mathrm{SiO}_{2}$ を用いた場合, 噴 霧量が少ないと透磁率の実部, 虚部共にわずかに Lichteneckerの対数混合則から計算される值からずれるにと どまった。しかし同じ濃度の水溶液を 2 倍量噴霧して Ni-Zn フェライト薄膜を堆積させた $\mathrm{SiO}_{2}$ を用いた場合, 複素比透 磁率の実部, 虚部共に低周波領域では Lichtenecker の対数混 合則から求めた值からさらにずれ，孤立モデルに近づいた。 濃度 D の水溶液を多量に噴霧した場合, $\mathrm{SiO}_{2}$ に堆積される $\mathrm{Ni}-\mathrm{Zn}$ フェライト薄膜の厚みが増加し $\mathrm{SiO}_{2}$ 粒子が孤立化す る割合が増加したためであると考えられる。

図 9 に濃度 D の水溶液を用いてスプレー法により $\mathrm{Ni}-\mathrm{Zn}$ フェライト被膜を堆積させた $\mathrm{SiO}_{2}$ を用いて作製した複合体 の複素比誘電率を示す。噴霧が多いほど実部, 虚部ともに 


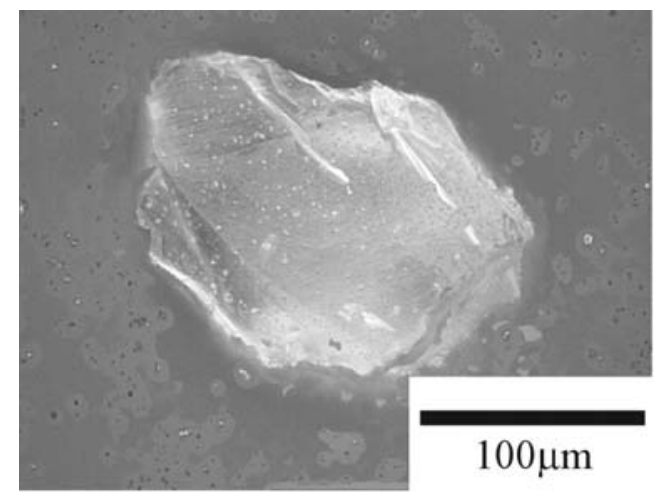

(a)

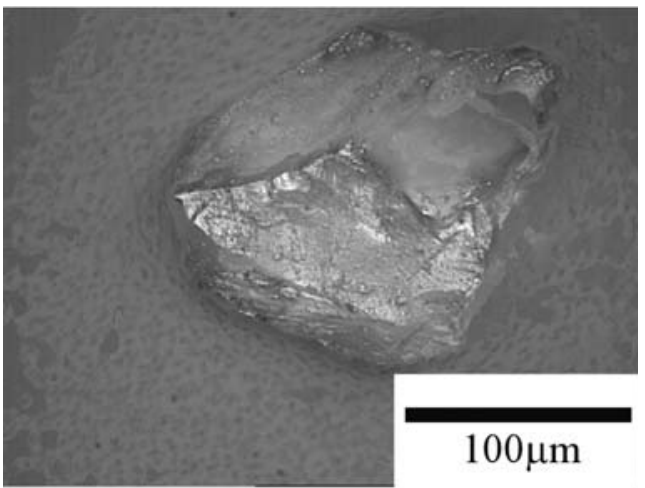

(b)

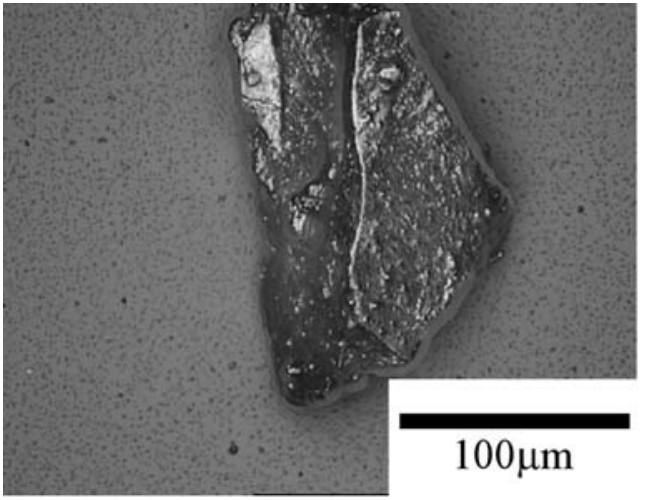

(c)

図 7 スプレー法で平均粒径約 $200 \mathrm{~mm}$ の $\mathrm{SiO}_{2}$ 粒子表面 に Ni-Zn フェライト被膜を作製した試料の光学顕微鏡 写真 : (a)石英砂，(b)濃度 A, (c)濃度 D の水溶液を 用いてスプレーした石英砂

Fig. 7. Microphotographs of (a) $\mathrm{SiO}_{2}$ and $\mathrm{SiO}_{2}$ coated by $\mathrm{Ni}-\mathrm{Zn}$ ferrite by using (b) solution A and (c) solution D. Average grain size of $\mathrm{SiO}_{2}$ is approximately $200 \mathrm{~mm}$.

低周波領域で值は大きくなった。1GHz 以下では虚部は周波 数に反比例しているので，低周波領域で虚部が大きくなる 原因は複合体の導電率が大きくなるためであると考えられ る。 $\mathrm{SiO}_{2}$ および今回用いた組成の $\mathrm{Ni}-\mathrm{Zn}$ フェライトは単体 では絶縁体であるので，導電率が大きくなった原因として

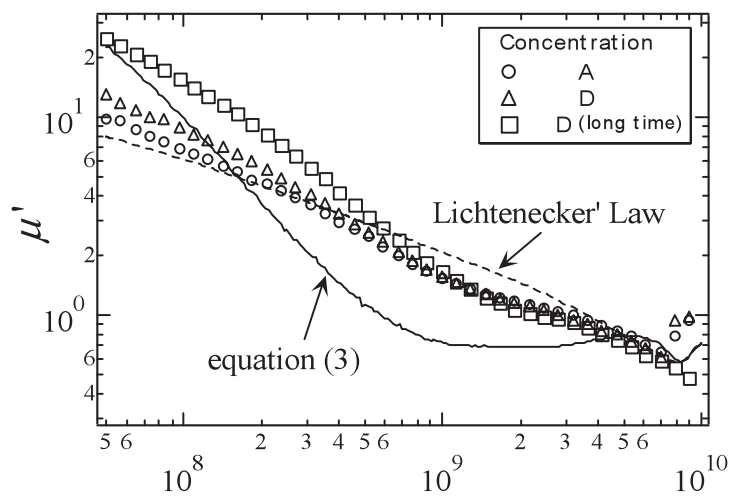

Frequency $[\mathrm{Hz}]$

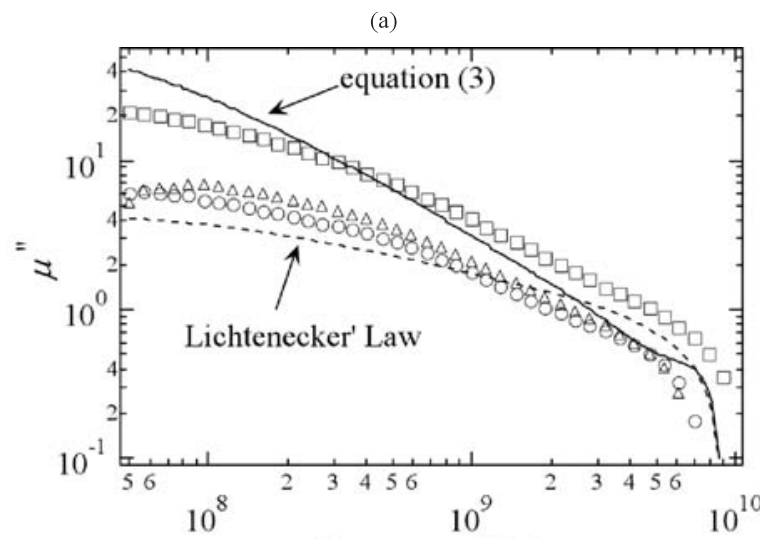

Frequency [Hz]

(b)

図 8 濃度 $\mathrm{A}$ および $\mathrm{D}$ の水溶液を用いてスプレー法に より作製した $\mathrm{SiO}_{2}$ を $70 \mathrm{~mol} \%$ と $\mathrm{Ni}-\mathrm{Zn}$ フェライト超微 粒子を $30 \mathrm{~mol} \%$ 混合した複合体の複素比透磁率 $\mu_{\mathrm{r}}{ }^{*}$

の周波数特性 (プロット)

Fig. 8. Frequency dependence of (a) the real part and (b) the imaginary part of $\mu_{\mathrm{r}}{ }^{*}$ for composites made of super fine grain of Ni-Zn ferrite- $30 \mathrm{~mol} \%$ and $\mathrm{SiO}_{2}-70 \mathrm{~mol} \%$ coated by $\mathrm{Ni}-\mathrm{Zn}$ ferrite thin film by the spray method using solutions $\mathrm{A}$ and D. Plots show measured values.

以下のことが考えられる。Ni-Zn フェライト中の鉄は通常 3 価であるが， $\mathrm{SiO}_{2}$ 粒子と複合体を形成することにより一部 の鉄が 2 価に変化し導電性が発現する。2 価の鉄の存在の 検証は現在研究中である。

図 10 に $\mu_{\mathrm{r}}^{*}$ の周波数特性が $\mathrm{SiO}_{2}$ 粒子が $\mathrm{Ni}-\mathrm{Zn}$ フェライト 媒質中で完全に孤立したモデルを用いて計算した $\mu_{\mathrm{r}}{ }^{*}$ の周 波数特性に最も近い試料のリターンロスの周波数特性を示 す。どの厚みにおいてもリターンロスは-20dB 以下にはなら なかった。この原因として図 8 に示すように複素比誘電率 の虚数部すなわち, 導電性が大きいためであると考えられ, 前述のように $\mathrm{SiO}_{2}$ 粒子を $\mathrm{Ni}-\mathrm{Zn}$ フェライト中に完全に孤立 するか $\mathrm{MnO}$ 等を適量添加することにより導電性が小さくす ることができればシミュレーションより求めた吸収特性に 近づくことが期待される。 


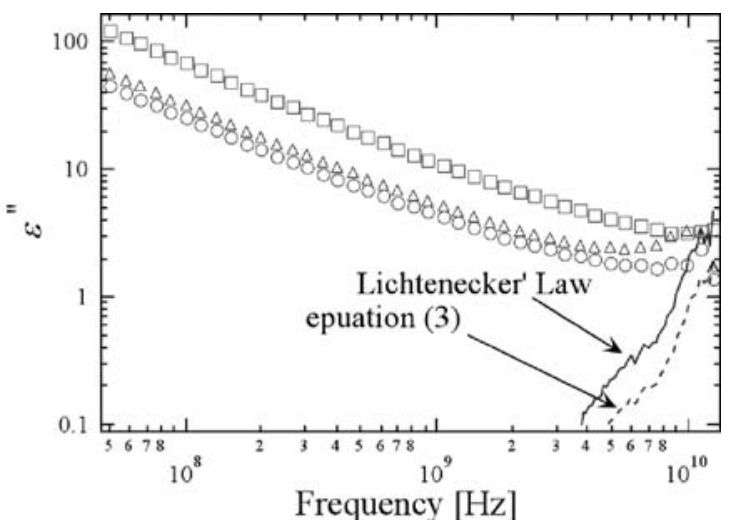

(a)

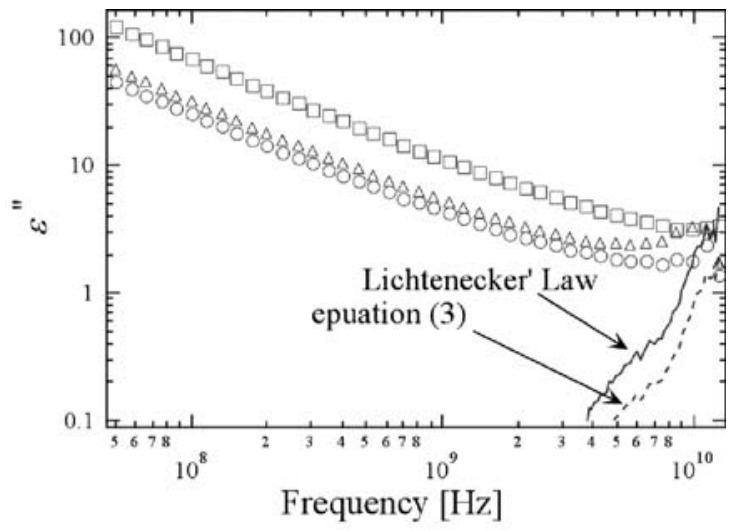

(b)

図 9 濃度 $\mathrm{A}$ および $\mathrm{D}$ の水溶液を用いてスプレー法に より作製した $\mathrm{SiO}_{2}$ を $70 \mathrm{~mol} \%$ と $\mathrm{Ni}-\mathrm{Zn}$ フェライト超微 粒子を $30 \mathrm{~mol} \%$ 混合した複合体の複素比誘電率 $\varepsilon_{\mathrm{r}}{ }^{*}$ の周波数特性 (プロット)

Fig. 9. Frequency dependence of (a) the real part and (b) the imaginary part of $\varepsilon_{\mathrm{T}}{ }^{*}$ for composites made of super fine grain of Ni-Zn ferrite- $30 \mathrm{~mol} \%$ and $\mathrm{SiO}_{2}-70 \mathrm{~mol} \%$ coated by $\mathrm{Ni}-\mathrm{Zn}$ ferrite thin film by the spray method using solutions $\mathrm{A}$ and $\mathrm{D}$. Plots show measured values

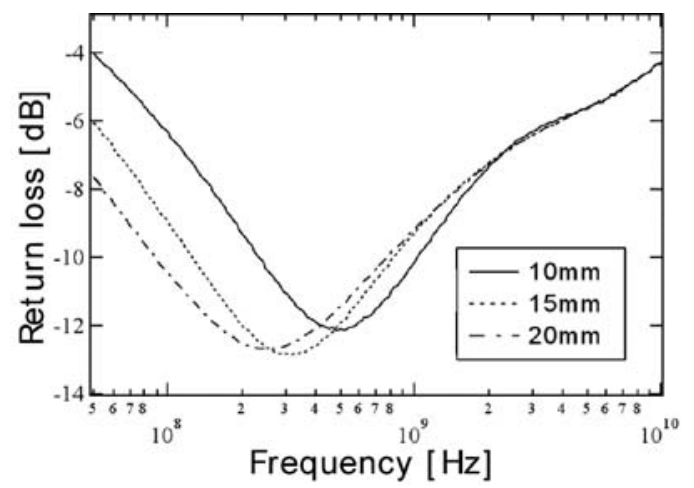

図 10 スプレー法で濃度 D の水溶液を用いて作製

した $\mathrm{SiO}_{2}$ 複合体の各試料厚のリターンロス

Fig. 10. Frequency dependences of the return loss for composite materials made of super fine grain of $\mathrm{Ni}-\mathrm{Zn}$ ferrite-30mol\% and $\mathrm{SiO}_{2}-70 \mathrm{~mol} \%$ deposited Ni-Zn ferrite by the spray method using solution $\mathrm{D}$

\section{5. 結 論}

(1) $\mathrm{Ni}-\mathrm{Zn}$ フェライトと $\mathrm{SiO}_{2}$ の複合体において $\mathrm{Ni}-\mathrm{Zn}$ フ エライト粒子を $\mathrm{SiO}_{2}$ 媒質中に孤立させることは $\mathrm{SiO}_{2}$ 超微粒 子を用いることで可能であるが，逆に $\mathrm{SiO}_{2}$ 粒子が $\mathrm{Ni}-\mathrm{Zn}$ フ ェライト媒質中で孤立させるには $\mathrm{Ni}-\mathrm{Zn}$ フェライトの超微 粒子を用いても現段階では不可能なことが分かった。

（2）スプレー製膜法を用いることによって $\mathrm{SiO}_{2}$ （石英 砂) 粒子表面に Ni-Zn フェライトの被膜の堆積が可能である ことが分かった。

（3） $\mathrm{Ni}-\mathrm{Zn}$ フェライト被膜を堆積させた $\mathrm{SiO}_{2}$ (石英砂) を用いて作製した複合体の複素比透磁率の值は $\mathrm{SiO}_{2}$ (石英 砂)粒子が Ni-Zn フェライト媒質中で孤立するモデルから算 出した值に近づくことが分かった。

(4) $\mathrm{SiO}_{2}$ 粒子が $\mathrm{Ni}-\mathrm{Zn}$ フェライト媒質中に完全に孤立し ていないと考えられ, $\mathrm{SiO}_{2}$ 粒子が $\mathrm{Ni}-\mathrm{Zn}$ フェライト媒質中 で完全に孤立したモデルによるシミュレーションで得られ る電磁波吸収特性は得られなかった。

\section{謝 辞}

$\mathrm{Ni}-\mathrm{Zn}$ フェライトの超微粒子を提供してくださった堺化 学工業（株）に深く感謝いたします。本研究は京都府地域 結集共同研究事業および同志社大学 R C A S T の支援のも と遂行されました。感謝いたします。

(平成 15 年 6 月 23 日受付, 平成 15 年 11 月 21 日再受付)

\section{文献}

(1) Y. Naito, K. Suetake, E. Fujiwara, and M. Sato : "the Characteristic of the Ferrite Absorbing Wall", IEICE Trans., Vol. J52-B, No.1, pp.26-30 (1969-1) (in Japanese)

内藤喜之・末武国弘・藤原英二・佐藤正明 :「フェライト吸収壁の電 波吸収特性」, 信学論 B, J52-B, 1, pp.26-30 (1969-1)

(2) Y. Kotsuka : "Ferrite Electromagnetic Wave Absorbers", J. Magn. Soc. Jpn, Vol. 21, pp. 1159-1166 (1997) (in Japanese)

小塚洋司:「フェライト電波吸収体」, 応用磁気学誌, 21, pp. 1159-1166 (1997)

( 3 ) H. Ueno, T. Kondo, and S. Yoshikado : "Development and Evaluation of the Composite Electromagnetic Wave Absorbers Made of Composite Ferrite", T. IEE Japan, Vol.22, pp.881-884 (1998) (in Japanese)

上野秀典・近藤隆俊・吉門進三:「複合電波吸収体材料の開発と評価」, 応用磁気学誌, 22, pp.881-884 (1998)

(4) T. Kondo and S. Yoshikado : "Electromagnetic Characteristics of a Ceramic Composite", J. Ceram. Soc. Japan, Vol.109, pp.326-331 (2001) (in Japanese) 近藤隆俊・吉門進三 :「セラミックス複合体の電磁気的特性につい て」, J. Ceram. Soc. Japan, 109, pp.326-331 (2001)

(5) H. Kusunoki, T. Kondo, and S. Yoshikado : "Improvement of the Electromagnetic Wave Absorbers of Ferrite- $\mathrm{SiO}_{2}$ Composites and the Evaluation of the Incident Angle Characteristics", T. IEE Japan, Vol.122-A, No.5, pp.485-492 (2002-5) (in Japanese)

楠 祐樹・近藤隆俊・吉門進三: 「フェライト・ $\mathrm{SiO}_{2}$ 複合電磁波吸収 体の吸収特性の改善および斜め入射特性の評価」, 電学論 A, 122, 5 , pp.485-492 (2002-5)

(6) H. Kusunoki, T. Kondo, K. Hiraki, K. Takada, and S.Yoshikado "Grain-size Dependence of Absorption Characteristics of the Electromagnetic Wave Absorbers of Ferrite- $\mathrm{SiO}_{2}$ Composites", IEEJ Trans. FM, Vol. 123, No.2, pp.125-131 (2003-2) (in Japanese)

楠 祐樹・近藤隆俊・平木聖大・高田和志・吉門進三:「フェライト・ $\mathrm{SiO}_{2}$ 複合電磁波吸収体の吸収特性の粒径依存性」, 電学論 $\mathrm{A}, 123,2$, pp. 125-131 (2003-2) 
(7) K. Lichtenecker and K. Rother : "die Herlritung des Logarithmischen Mischungsgesetzes aus Allgemeinen Prinzipien der Stationön Ströung", Phys. Z, Vol.32, pp. 255-260 (1931)

(8) A. Takayama, K. Kondo, M. Okuya, and S. Kaneko : "Preparetion and Characterization of NiZn Ferrite Thin Films by a Spray Pyrolysis Deposition Method", J. Ceram. Soc. Japan, Vol.110, pp.916-920 (2002) (in Japanese)

高山昭夫・近藤和匡・奥谷昌之・金子正治：「スプレー熱分解法によ る NiZn フェライト薄膜の作製とその特性」, J. Ceram. Soc. Japan, 110, pp.916-920 (2002)

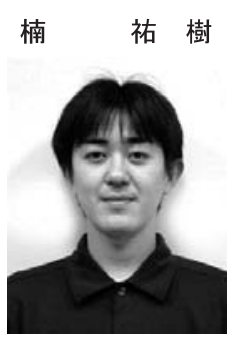

（非会員） 1978 年 6 月 2 日生まれ。2001 年 4 月同志社大学大学院工学研究科電気工学専 攻博士前期課程入学。現在に至る。電子情報通 信学会会員。

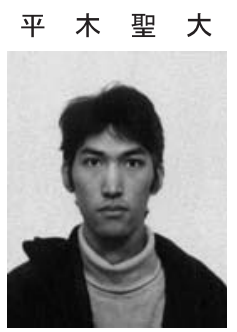

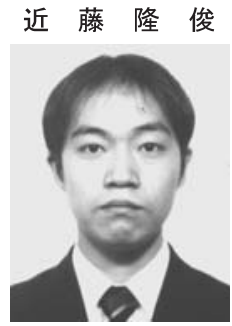

（非会員） 1975 年 10 月 18 日生まれ。1998 年 4 月同志社大学大学院工学研究科電気工学専攻 博士前期課程入学。現在, 東日本旅客鉄道 (株) 勤務。

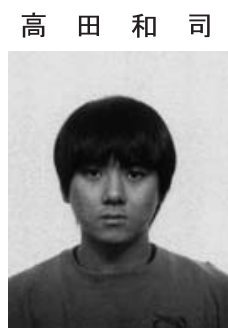

（非会員） 1978 年 11 月 10 日生まれ。1998 年 4 月同志社大学工学部電気工学科入学。現在に至 る。

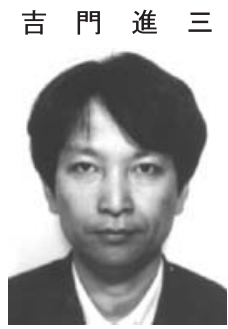

正員） 1952 年 11 月 13 日生まれ。1978 年 3 月 電気通信大学大学院電気通信学研科修士課程 修了。1982 年 4 月同志社大学工学部助手。助教 授を経て 1995 年教授。現在に至る。博士（工 学)。主として電気電子材料工学に関寸る研究 に従事。日本物理学会, 応用物理学会, 電子情 報通信学会会員。 